7. Reprod. Fert. (1967) 13, 127-132

\title{
THE CONTENT OF THE PRINCIPAL INORGANIC IONS AND CARBON DIOXIDE IN UTERINE FLUIDS OF THE DOMESTIC HEN
}

\author{
M. H. EL JAGK* AND P. E. LAKE \\ A.R.C. Poultry Research Centre, King's Buildings, West Mains Road, Edinburgh
}

(Received 14th April 1966)

\begin{abstract}
Summary. A method was devised to collect uncontaminated fluid from the uterus (shell gland) of the laying, domestic fowl at two different stages of formation of the egg in the organ.

There was a marked difference between the composition of the uterine fluid found during the early stages of egg formation in the uterus and that found within about $2 \mathrm{hr}$ of oviposition. The concentration of sodium fell from $139 \cdot 1$ to $42.8 \mathrm{~m}$-moles/l, whilst that of potassium rose from 15.9 to $75 \mathrm{~m}$-moles/l, at oviposition. The amounts of calcium and magnesium were found to be higher around the time of egg laying and was most probably associated with the deposition of egg shell.

The significance of changes in the ionic composition of uterine fluid to the storage and movement of spermatozoa in the oviduct of the hen has been discussed.
\end{abstract}

\section{INTRODUCTION}

The general histological structure of the oviduct of the domestic fowl (Gallus domesticus) has been investigated by Surface (1912) and Bradley (1928) and the secretory glands in different parts have been studied by Richardson (1935), Fujii (1963), Johnston, Aitken \& Wyburn (1963) and Aitken \& Johnston (1963). The $\mathrm{pH}$ of the secretions of the different regions of the oviduct has been determined by Buckner \& Martin (1929), Ogasawara, Van Krey \& Lorenz (1964) and Winget, Mepham \& Averkin (1965). The latter demonstrated that the $\mathrm{pH}$ of the uterine fluids changed as the egg passed through the oviduct.

The avian ovum is surrounded by albumen and a thin membranous envelope when it passes from the isthmus into the uterus (shell gland). An aqueous solution of salts is added through the envelope for about the first $5 \mathrm{hr}$ that the egg is in the uterus and, as a result, it is said to be 'plumped' (Burmester, 1940). For about another 13 to $15 \mathrm{hr}$, before oviposition occurs, shell is added to the surface of the egg and fluid is always present in the uterus during this pre-oviposition period. Spermatozoa reside during the prolonged period of fertility in the fowl and turkey hen, after a single insemination, in tubular glands of the epithelium at the junction of the uterus and vagina (Bobr, Lorenz \& Ogasawara, 1962, 1964; Bobr, Ogasawara \& Lorenz, 1964; Fujii \& Tamura,

* Present address: Faculty of Agriculture, University of Khartoum, Shambat, Khartoum North, Sudan. 
1963; Verma \& Cherms, 1965) and it is feasible to suppose that fluid secretions in the uterus and vicinity could influence the movement of spermatozoa up to the infundibulum where fertilization occurs. However, there is little precise information about the chemical composition of the secretions of the uterus and whether any changes occur with the passage of the egg through the oviduct.

Beadle, Conrad \& Scott (1938) attempted to collect 'plumping' fluid from the uterus of hens by inserting a rubber tube per vaginam but it was invariably contaminated by cloacal contents. Hoover \& Smith (1952) pushed glass catheters (with various sizes of perforated, egg-shaped bulbs on one end) into the shell-gland per vaginam; trauma developed occasionally and the largest catheter ( $50 \mathrm{ml}$ capacity) caused haemorrhage.

A method has been devised to collect uncontaminated fluid from the uterus of the laying hen at two different stages of development of the egg in the uterus. The ionic content has been examined and the results are reported herein.

\section{MATERIAL AND METHODS}

Uterine fluids were collected from laying hens of the Breeding-Intensity cross of Brown Leghorns kept at the Poultry Research Centre, Edinburgh (Blyth, 1954). They were housed in single, battery cages so that individual egg laying records could be made accurately. The birds were fed a breeders' ration (El Jack \& Lake, 1966) and given $14 \mathrm{hr}$ of artificial light daily.

\section{Collection of uterine fluids}

Fluids were collected during two stages of egg formation in the uterus and were designated as 'plumping' and 'oviposition' fluids respectively. 'Plumping' fluid is added to the egg during the first $5 \mathrm{hr}$ that it is present in the uterus when it is composed merely of yolk and albumen and covered with a soft, membranous covering (Burmester, 1940). 'Oviposition' fluid is defined as that fluid obtained from the uterus when a normal, hard-shelled egg is present and is expected to be laid within $2 \mathrm{hr}$ of the time of examination.

Hens were selected at the appropriate times and the presence of a membranous or hard-shelled egg was confirmed by palpitation per cloacam. They were anaesthetized with 0.5 to $0.6 \mathrm{ml}$ Nembutal (Pentobarbitone Sodium, Abbott Laboratories Ltd) given intravenously. Each hen was laid on its back, feathers were removed from the left side of the abdomen where a neat, small incision was made which allowed the introduction of one or two fingers of the operator's left hand. The cloaca was thoroughly cleaned and pressure was applied to the anterior end of the uterus. A plastic funnel was placed in the mouth of a calibrated, Pyrex centrifuge tube held in the right hand. Continuous pressure was applied to the uterus until the egg began to appear at the mouth of the vagina; as soon as it was forced from the vagina a second person removed the egg and the fluid which followed was ejected into the graduated, Pyrex tube. All the fluid was extracted without contamination from cloacal material by gently massaging the uterus. Liquid paraffin was placed in the tube to prevent the loss of carbon dioxide from the fluid. Volumes of fluid ranging from 0.50 to $1.70 \mathrm{ml}$ were easily obtained by this method. After the operation, which lasted for $5 \mathrm{~min}$, the everted vagina was allowed to resume its normal position 
and the abdominal incision was closed by suture. Frequent observations were made subsequently on the general health and laying record of the birds and all continued to lay normally.

'Plumping' fluid was collected from fifteen hens for the estimation of inorganic ions and in eight of these carbon dioxide was determined in addition. 'Oviposition' fluid was obtained from fifteen hens for all the analyses, including carbon dioxide.

Analytical procedures

Duplicate aliquots of 0.10 and $0.05 \mathrm{ml}$ fluid were used directly for the estimation of chloride and carbon dioxide respectively. The remaining fluid in the stoppered, graduated, Pyrex tube was recorded accurately and a known volume of $0.10 \mathrm{~N}-\mathrm{HCl}$ added. This solution was thoroughly mixed and left standing overnight. Afterwards the following dilutions were made directly with doublyglass-distilled water for analyses: magnesium $(\times 20)$, calcium $(\times 100)$, potassium $(\times 200)$ and sodium $(\times 1500)$.

Sodium, potassium, calcium and magnesium concentrations in the uterine fluids were estimated by atomic absorption spectrophotometry (Gatehouse \& Willis, 1961). The purity of the water was always checked by running samples as blanks in the atomic absorption spectrophotometer.

Chloride was determined by electrometric titration with silver ions (Cotlove, Trantham \& Bowman, 1958) and carbon dioxide by gas chromatography (El Jack \& Lake, 1966).

\section{TABLE 1}

THE CONTENT OF THE PRINCIPAL INORGANIC IONS (mEq/l; MEAN \pm s.E. AND m-moles/l) IN THE 'PLUMPING' AND 'OVIPOSITION' FLUIDS FROM THE UTERUS OF BROWN LEGHORN HENS. THE VALUES ARE THE MEANS OBTAINED FROM FIFTEEN HENS EXCEPT IN THE CASE OF CARBON DIOXIDE IN 'PLUMPING' FLUID WHERE ONLY EIGHT HENS WERE USED

\begin{tabular}{|c|c|c|c|c|}
\hline \multirow{2}{*}{ Inorganic ions } & \multicolumn{2}{|c|}{ 'Plumping' fluid } & \multicolumn{2}{|c|}{ 'Oviposition' fuid } \\
\hline & $m E q / l$ & $m$-moles $/ l$ & $m E q / l$ & m-moles $/ l$ \\
\hline $\begin{array}{l}\text { Cations } \\
\text { Sodium } \\
\text { Potassium } \\
\text { Calcium } \\
\text { Magnesium } \\
\text { Total }\end{array}$ & $\begin{array}{r}139 \cdot 10 \pm 4.58 \\
15 \cdot 91 \pm 0.79 \\
28 \cdot 30 \pm 1 \cdot 35 \\
2 \cdot 74 \pm 0.30\end{array}$ & $\begin{array}{r}139 \cdot 10 \\
15 \cdot 91 \\
14 \cdot 10 \\
1 \cdot 36 \\
170 \cdot 47\end{array}$ & $\begin{array}{l}42 \cdot 84 \pm 2 \cdot 11 \\
75 \cdot 03 \pm 3 \cdot 0 \\
51 \cdot 60 \pm 6 \cdot 85 \\
20 \cdot 35 \pm 2 \cdot 45\end{array}$ & $\begin{array}{r}42 \cdot 80 \\
75 \cdot 03 \\
25 \cdot 80 \\
10 \cdot 03 \\
153 \cdot 66\end{array}$ \\
\hline $\begin{array}{l}\text { Anions } \\
\text { Chloride } \\
\text { Carbon dioxide } \\
\text { Total }\end{array}$ & $\begin{array}{l}79 \cdot 90 \pm 1 \cdot 73 \\
82 \cdot 47 \pm 1 \cdot 75\end{array}$ & $\begin{array}{r}79.90 \\
82.47 \\
162.37\end{array}$ & $\begin{array}{l}63 \cdot 42 \pm 3 \cdot 89 \\
91 \cdot 26 \pm 2 \cdot 79\end{array}$ & $\begin{array}{r}63.42 \\
91.26 \\
154.68\end{array}$ \\
\hline
\end{tabular}

\section{RESULTS}

The contents of the principal inorganic ions and carbon dioxide found in the uterine fluids are summarized in Table 1. The fluid differed in composition depending upon the stage of egg formation. Sodium was the major cation in 
'plumping' fluid (139.10 $\mathrm{mm} / \mathrm{l})$ and potassium the major cation in 'oviposition' fluid $(75.03 \mathrm{~mm} / \mathrm{l})$. Calcium and magnesium concentrations were considerably greater in 'oviposition' than in 'plumping' fluid. The amounts of chloride and carbon dioxide in 'plumping' fluid were almost equal but the latter was the dominant anion in 'oviposition' fluid.

\section{DISCUSSION}

The formation of the egg of the fowl is a complex process. The ovary contributes the large, yolky ovum and the oviduct provides the albumen (protein and an aqueous solution of electrolytes and non-electrolytes), the membranes and the shell. Attention in the present work was focussed on aspects of the electrolyte composition of uterine fluid since the latter could feasibly be supposed to play a part, together with muscular activity, in the movement of spermatozoa from the utero-vaginal storage sites (Bobr et al., 1962, 1964; Fujii \& Tamura, 1963) after natural or artificial insemination. It is also possible that the aqueous solutions which pass into the egg albumen during the presence of the egg in the uterus might influence pre-oviposital embryonic development.

Beadle et al. (1938) reported differences in the composition of 'plumping' fluid compared with those in the present work. However, they experienced trouble in catheterizing the uterus for the collection of the fluid and used less reliable methods of estimating the various ions. The amounts of magnesium and calcium found in 'plumping' fluid in the present work were higher than those reported by Beadle et al. (1938); it seems probable that this is due to the fact that the atomic absorption spectrophotometer is more sensitive than the chemical precipitation methods used in the earlier work. Nevertheless, there was general agreement in that the level of calcium was considerably higher than that of blood plasma. A most interesting fact about the composition of 'plumping' fluid was the presence of appreciable amounts of carbon dioxide and calcium, which is undoubtedly associated with the mechanism of shell deposition. A large amount of calcium $(2.0 \mathrm{~g})$ is required in a relatively short time to form an egg shell (Romanoff \& Romanoff, 1949).

The composition of the 'oviposition' fluid was different from that of 'plumping' fluid. The sodium concentration in the former was much less than that in the latter and it is very difficult to suggest a reason for this dramatic fall. Sodium does not appear to enter the egg, because the amount inside the egg remains fairly constant (Draper, 1966). The amount of potassium in 'oviposition' fluid was extremely high and this may be correlated with recent observations (Draper, 1966) that the concentration of potassium in the egg white (albumen) remains low until an appreciable degree of calcification of the egg has occurred, when it begins to rise. The magnesium concentration of the 'oviposition' fluid was high and more than seven times that in 'plumping' fluid. This may be associated with the fact that the egg shell of the domestic hen accumulates about $21.0 \mathrm{mg}$ of magnesium (Romanoff \& Romanoff, 1949).

A few $\mathrm{pH}$ measurements were made on the 'plumping' and 'oviposition' fluids and they were found to be high (7.65 and 7.71 respectively) which agreed with previous observations made on the mucosal fluids in vivo (Ogasawara 
et al., 1964). The secretion of glands in the utero-vaginal junction, where the spermatozoa are stored, is of a similar high pH (Ogasawara et al., 1964) and the presence of bicarbonate may largely account for the alkalinity of these secretions.

If the presence of spermatozoa in the tubular glands of the utero-vaginal junction (Bobr et al., 1962, 1964; Fujii \& Tamura, 1963) during the prolonged fertility period of a hen means that spermatozoa are naturally stored in these sites, then they must, at some time, be released from the storage glands and travel up to the infundibulum where fertilization occurs. Peristaltic activity of the oviduct must play a large part in the migration and it remains to be investigated whether the changing composition of the fluids in the vicinity of the utero-vaginal junction may be of importance for the storage and activation of spermatozoa. Several aspects of the composition of the uterine fluid of the hen are pertinent to this discussion in the light of existing knowledge of factors influencing the activity of spermatozoa. For example, the uterine and tubal fluids of rabbits contain a high amount of bicarbonate and carbon dioxide (Vishwakarma, 1962; Hamner \& Williams, 1964; Williams, Weinman \& Hamner, 1964) and Williams et al. (1964) reported that the presence of pure bicarbonate $\left(2.36\right.$ to $\left.3.54 \times 10^{-3} \mathrm{M}\right)$ in diluent media increased considerably the respiration of rabbit, cock, bull and human spermatozoa. The effect of bicarbonate on rabbit spermatozoa could be duplicated with succinate and the authors concluded that bicarbonate increased the rate of respiration by more efficiently coupling glycolysis with the tricarboxylic acid cycle. Potassium in certain concentrations can stimulate motility of fowl spermatozoa (Wales \& White, 1958). In certain circumstances the presence of carbon dioxide in artificial media has led to considerable prolongation of the viability of fowl spermatozoa in vitro (Hobbs \& Harris, 1963) and the motility of spermatozoa can be inhibited by carbon dioxide (Schindler \& Nevo, 1962). Observations such as these indicate that the uterine fluids of the domestic hen contain chemical constituents which are capable of influencing the activity of spermatozoa in several ways.

Spermatozoa can ascend the oviduct of the hen very rapidly (Mimura, 1939) and the peristaltic activity of the organ must be assumed to play a large part in the process. In view of the information obtained on the high concentrations of calcium and potassium at times in the fluids of the uterus, their significance in regulating oviduct movements might be considered in future investigations. It is well known that potassium and calcium ions play a part in regulating smooth muscle contractility (Burnstock, Holman \& Prosser, 1963) and thus the great increase in potassium concentration in uterine fluid around the time of oviposition might be investigated for possible stimulatory effects on the muscular activity of the vagina and uterus and the expulsion of spermatozoa from their residence sites to begin their upward movement in the oviduct.

\section{ACKNOWLEDGMENTS}

The authors are grateful to Dr M. H. Draper for his interest in this work, and to Mr J. M. Stewart and Mr J. Peddie for technical help. Mr J. Filshie very kindly gave advice on the techniques of atomic absorption spectrophotometry. 


\section{REFERENCES}

Aitken, R. N. C. \& Johnston, H. S. (1963) Observations on the fine structure of the infundibulum of the avian oviduct. 7. Anat. 97, 87.

Beadle, B. W., Conrad, R. M. \& Scott, H. M. (1938) Composition of the uterine secretion of the domestic fowl. Poult. Sci. 17, 498.

Blyth, J. S. S. (1954) Notes on the Poultry Research Centre flock of Brown Leghorns. Wld's Poult. Sci. 7. 10, 140.

Bobr, L. W., Lorenz, F. W. \& Ogasawara, F. X. (1962) The role of the uterovaginal junction in storage of cock spermatozoa. (Abstract.) Poult. Sci. 41, 1628.

Bobr, L. W., Lorenz, F. W. \& Ogasawara, F. X. (1964) Distribution of spermatozoa in the oviduct and fertility in domestic birds. I. Residence sites of spermatozoa in fowl oviducts. 7 . Reprod. Fert. 8,39 .

Bobr, L. W., Ogasawara, F. X. \& Lorenz, F. W. (1964) Distribution of spermatozoa in the oviduct and fertility in domestic birds. II. Transport of spermatozoa in the fowl oviduct. 7. Reprod. Fert. 8, 49.

Bradley, O. G. (1928) Notes on the histology of the oviduct of the domestic hen. 7. Anat. 62, 339.

Buckner, G. D. \& Martin, J. H. (1929) The hydrogen ion concentration of the reproductive organs of the White Leghorn chicken. Am. 7. Physiol. 89, 164.

Burmester, B. R. (1940) A study of the physical and chemical changes of the egg during its passage through the isthmus and uterus of the hen's oviduct. 7. exp. Zool. 84, 445.

Burnstock, G., Holman, M. E. \& Prosser, G. L. (1963) Electrophysiology of smooth muscle. Physiol. Rev. 43, 482 .

Cotlove, E., Trantham, H. V. \& Bowman, R. L. (1958) An instrument and method for automatic, rapid, accurate and sensitive titration of chloride in biological samples. 7. Lab. clin. Med. 51, 461 .

Draper, M. H. (1966) The transport of minerals to the white of the hen's egg. Proc. 13th World Poult. Congr. Kiev, p. 333.

EL JACK, M. H. \& LAKe, P. E. (1966) The distribution of the principal inorganic ions in venous blood of the adult domestic cock and the content of carbon dioxide in the plasma. Br. Poult. Sci. 7, 315.

FujII, S. (1963) Histological and histochemical studies on the oviduct of the domestic fowl with special reference to the region of uterovaginal junction. Archvm histol. jap. 23, 447.

FujII, S. \& Tamura, T. (1963) Location of sperms in the oviduct of the domestic fowl with special reference to the storage of sperms in the vaginal gland. 7. Fac. Fish. Anim. Husb. Hiroshima Univ. $5,145$.

Gatehouse, B. M. \& Willis, J. B. (1961) Performance of a simple atomic absorption spectrophotometer. Spectrochim. Acta, 17, 710.

Hamner, C. E. \& Williams, W. L. (1964) Effect of bicarbonate on the respiration of spermatozoa. (Abstract.) Fedn Proc. Fedn Am. Socs exp. Biol. 23, 430.

Hoвbs, T. D. \& HARRIs, G. G. (1963) Effect of freezing point depression and $\mathrm{CO}_{2}$ on motility and fertility of chicken spermatozoa stored in $\mathrm{CO}_{2}$ extenders. Poult. Sci. 42, 388.

Hoover, G. N. \& Smith, A. H. (1952) Secretion of fluid by the shell gland of the laying hen. Poult. Sci. 37,467 .

Johnston, H. S., Attken, R. N. C. \& Wyburn, G. M. (1963) The fine structure of the uterus of the domestic fowl. 7. Anat. 97, 333.

Mimura, H. (1939) On the mechanism of travel of spermatozoa through the oviduct in the domestic fowl, with special reference to the artificial insemination. Okajimas Folia anat. jap. 17, 459.

Ogasawara, F. X., VAN Krey, H. P. \& Lorenz, F. W. (1964) Hydrogen ion concentration of the oviduct of the laying domestic fowl. Poult. Sci. 43, 3.

Richardson, K. G. (1935) The secretory phenomena in the oviduct of the fowl, including the process of shell formation examined by the microincineration technique. Phil. Trans. R. Soc. B, 225, 149.

Romanoff, A. L. \& Romanoff, A. J. (1949) The avian egg. Wiley, New York.

Schindler, H. \& Nevo, A. (1962) Reversible inactivation and agglutination of fowl and bull spermatozoa under anaerobic conditions. 7 . Reprod. Fert. 4, 251.

Surface, F. M. (1912) The histology of the oviduct of the domestic hen. Bull. Me agric. Exp. Stn, 206, 395.

Verma, O. P. \& Cherms, F. L. (1965) The appearance of sperm and their persistency in storage tubules of turkey hens after a single insemination. Poult. Sci. 44, 609.

Vishwakarma, P. (1962) The pH and bicarbonate-ion content of the oviduct and uterine fluids. Fert. Steril. 13, 481 .

Wales, R. G. \& White, I. G. (1958) The effect of alkali metal, magnesium and calcium ions on the motility of fowl spermatozoa. Aust. 7. biol. Sci. 11, 589.

Williams, W. L., Weinman, D. E. \& Hamner, C. E. (1964) Effect of the female reproductive tract on spermatozoa. Proc. 5th int. Congr. Anim. Reprod. and A.I., Trento, Section 2, p. 367.

Winget, C. M., Mepham, C. A. \& Averkin, E. G. (1965) Variations in intrauterine pH within a circadian rhythm (Gallus domesticus). Am. 7. Physiol. 208, 1031. 